\title{
Trapezoidal Control Integrating the Losses of an Electric Car Power Train
}

\section{Souhir Tounsi}

National School of Electronics and Telecommunications of Sfax, Setit-Research Unit, Sfax University, Sfax, Tunisia

Email address:

souhir.tounsi@enetcom.rnu.tn

\section{To cite this article:}

Souhir Tounsi. Trapezoidal Control Integrating the Losses of an Electric Car Power Train. International Journal of Electrical Components and Energy Conversion. Vol. 1, No. 4, 2015, pp. 83-91. doi: 10.11648/j.ijecec.20150104.11

\begin{abstract}
In this paper, we present a modeling approach of the power chain based on the trapezoidal control, including the losses of the power train of an electric car. This modeling approach is parameterized leading to a problem of optimization of the parameters influencing the losses which leads to an improvement in the autonomy. This model approach is implanted under the simulation environment Matlab-Simulink. Simulation results are encouraging and opening track search for work optimization and experimental validation of the developed model.
\end{abstract}

Keywords: Trapezoidal Control, Electric Cars, Losses, Autonomy, Modeling, Simulations

\section{Introduction}

In this paper, we present a trapezoidal control strategy of a synchronous permanent magnet motor with axial flux, incorporating the losses of the power train of an electric car. The model developed is highly parameterized and poses a problem of parameters influencing losses optimization to improve the autonomy of the car. This control strategy is compatible to systemic design process of all motor-converter detailed in [1-5].

In this context the paper is organized in three parts to knowledge:

- The first part concerns the modeling of the components of the power chain under the Matlab-Simulink environment.

- The second part describes the different models coupling principle.

- The third part illustrates and describes the main results of simulations.

\section{Principle of the Control Strategy}

The trapezoidal command allow to impose phase currents with the back electromotive forces (technique of back electromotive force compensation) leading to a reduction in consumption for a stationary required driving power by the vehicle. Indeed, four control loops for providing the shape and amplitude of the ideal supply voltages of the motor. A control loop providing the amplitude of the reference currents and three control current loop delivering the phase voltages supplying motor $[1,2]$.

\section{Model of the Motor-Converter}

The engine is powered by a two-level voltage inverter with IGBT. Each phase of the motor is equivalent to a resistor in series with an inductance and a back electromotive force. The three phase's voltage of the model is described by the following equations [1-5]:

$$
\begin{aligned}
& \mathrm{u}_{1}=\mathrm{R} \times \mathrm{i}_{1}+(\mathrm{L}-\mathrm{M}) \times \frac{\mathrm{di}_{1}}{\mathrm{dt}}+\mathrm{e} 1 \\
& \mathrm{u}_{2}=\mathrm{R} \times \mathrm{i}_{1}+(\mathrm{L}-\mathrm{M}) \times \frac{\mathrm{di}_{2}}{\mathrm{dt}}+\mathrm{e} 2 \\
& \mathrm{u}_{3}=\mathrm{R} \times \mathrm{i}_{3}+(\mathrm{L}-\mathrm{M}) \times \frac{\mathrm{di}_{3}}{\mathrm{dt}}+\mathrm{e} 3
\end{aligned}
$$

Where $\mathrm{R}, \mathrm{L}, \mathrm{M}$ are respectively the resistance, inductance and mutual inductance of the motor, $\mathrm{i}_{\mathrm{i}}$ and $\mathrm{u}_{\mathrm{i}}$ are respectively the current and the voltage of the $i$ phase.

The electromagnetic torque is given by the following relationship [1-12]:

$$
\mathrm{T}_{\mathrm{em}}=\frac{1}{\Omega}\left(\mathrm{e}_{1} \times \mathrm{i}_{1}+\mathrm{e}_{2} \times \mathrm{i}_{2}+\mathrm{e}_{3} \times \mathrm{i}_{3}\right)
$$

Where $e_{i}$ is the back electromotive force of the $i$ phase.

The model of the motor-converter is implanted under the Matlab-Simulink environment according to the following block diagram: 


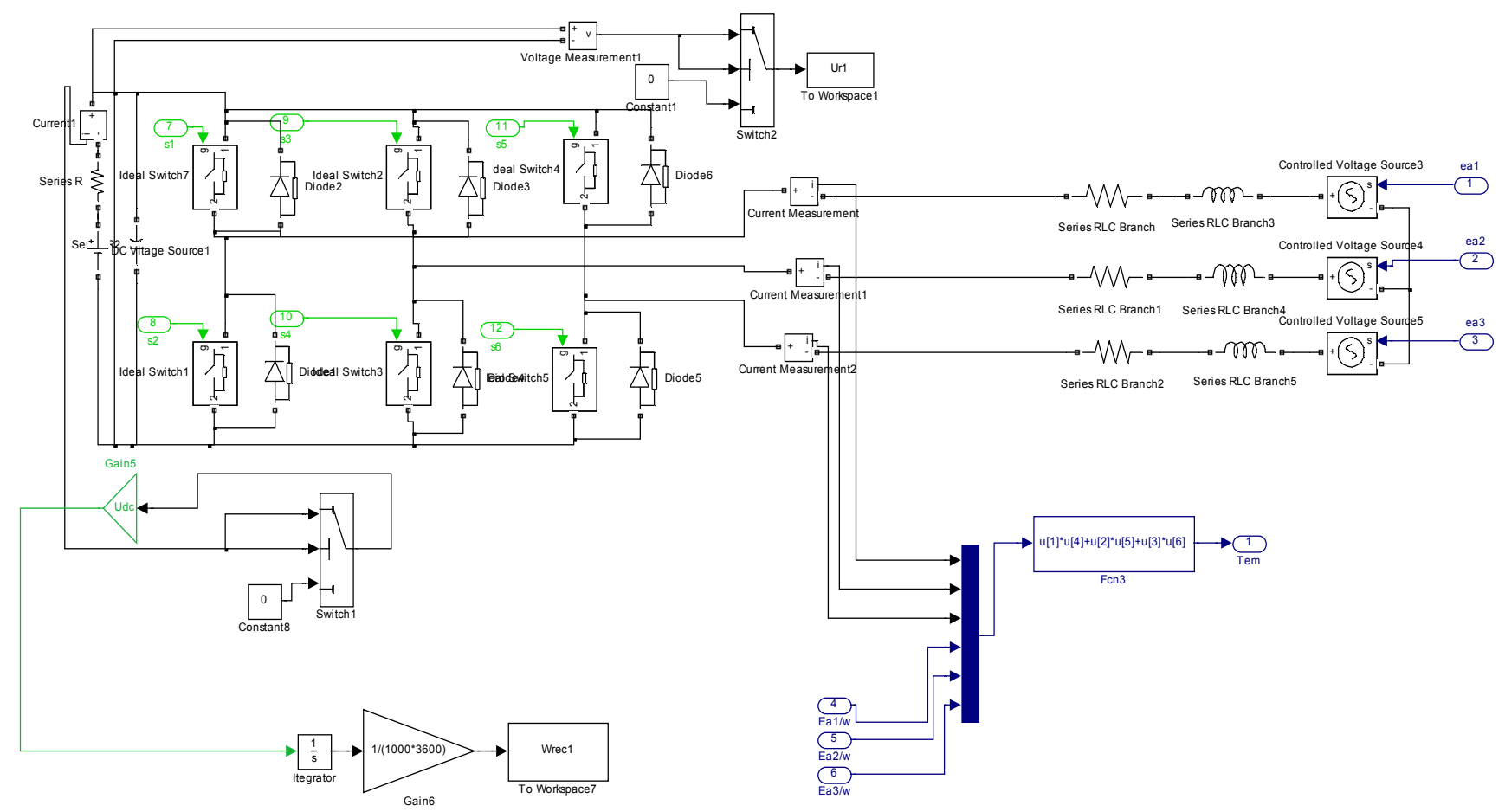

Figure 1. Simulink Model of the motor-converter.

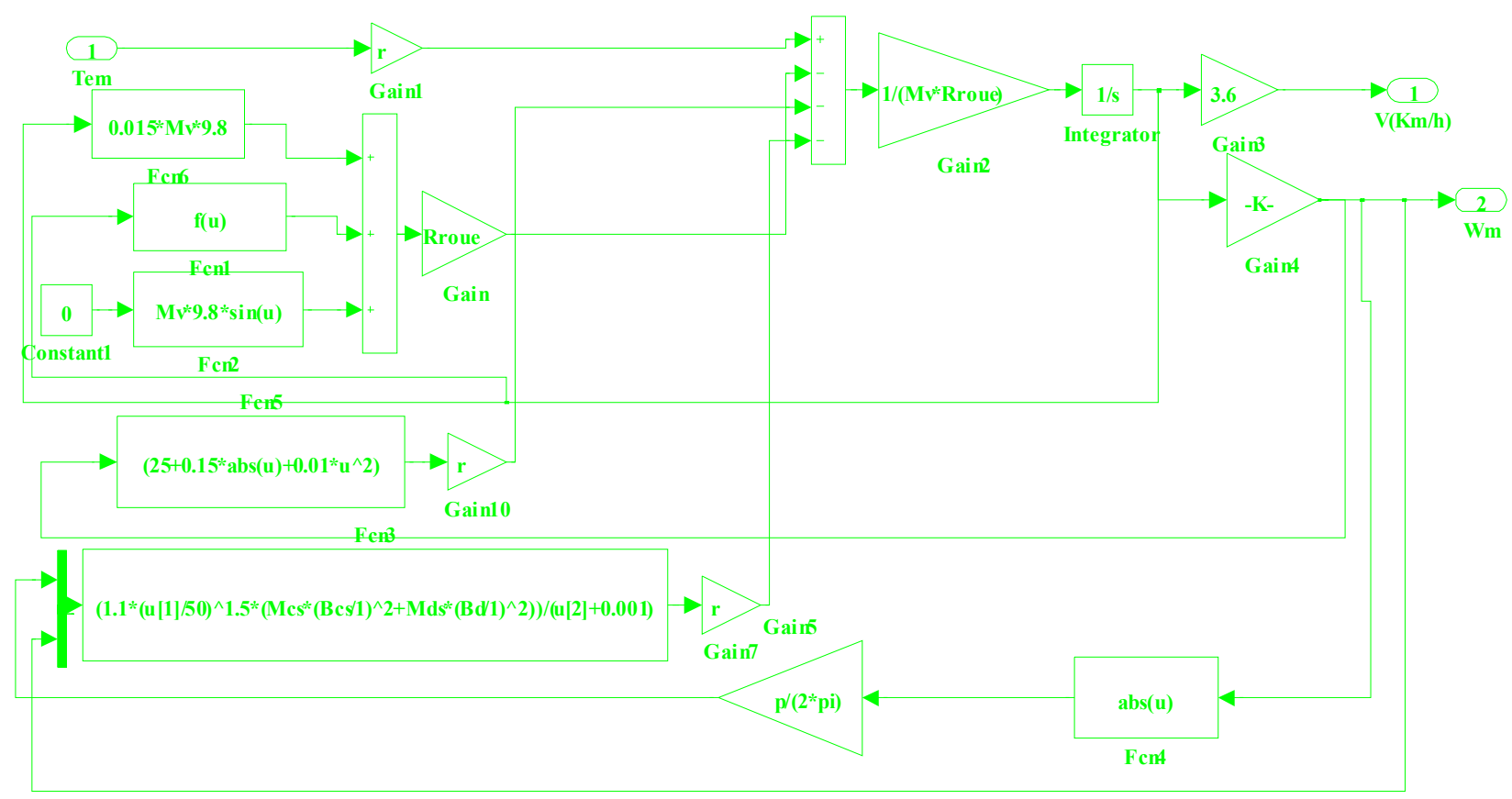

Figure 2. Simulinkmodelofthemotionequation.

\section{Equation of Movement}

The vehicle motion equation is derived from the fundamental relationship of dynamics [1-12]:

$$
\left(M_{v} \times R_{r}\right) \times \frac{d V}{d t}=r_{d} \times\left(T_{\text {em }}-T_{f}-T_{\text {mec }}\right)-\left(F_{r}+F_{a}+F_{c}\right) \times R_{r}
$$

Where $F_{r}$ is the rolling resistance force, $F_{a}$ is the aerodynamic force, $F_{c}$ is the force of gravity, $r_{d}$ is the amplification ratio, $\mathrm{T}_{\mathrm{em}}$ is the electromagnetic torque, $\mathrm{T}_{\mathrm{f}}$ is iron losses torque, $\mathrm{T}_{\text {mec }}$ is the mechanical losses torque, $\mathrm{R}_{\mathrm{r}}$ is the radius of the wheel of the car, $v$ is the speed of the car and $M_{v}$ and the mass of the car.

The equation of motion of the vehicle is implanted under the Matlab / Simulink environment according to the following figure: 


\section{Speed Regulator}

The speed regulator allows to adjust the amplitude of reference currents. Indeed, the reference speed is compared to the response speed of the electric car. The output of the comparator drives a proportional integral regulator type for providing the value of the reference currents amplitude minimizing the error between the reference speed and the response speed.

The Simulink model the speed regulator is illustrated by the following figure:

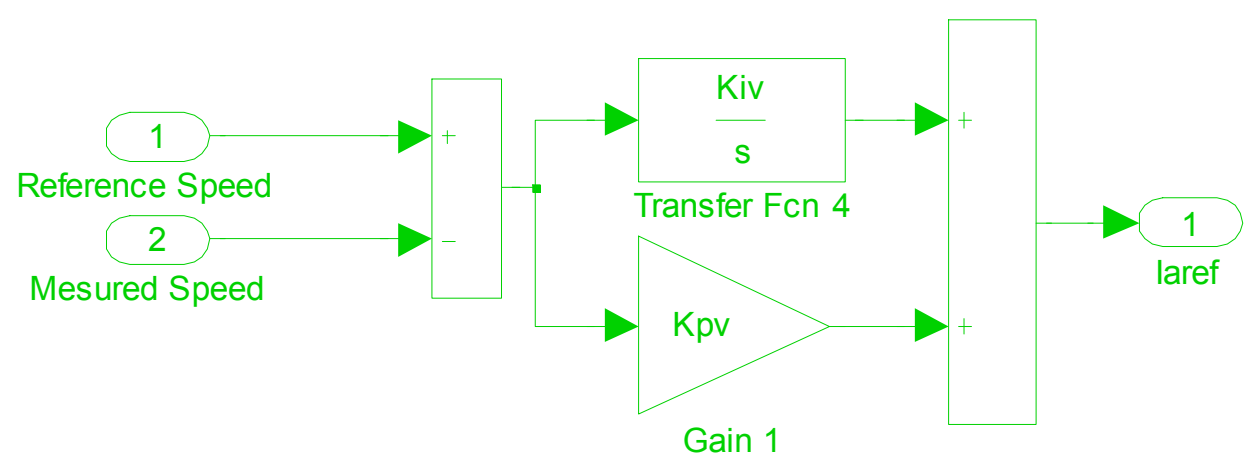

Figure 3. Speedregulator.

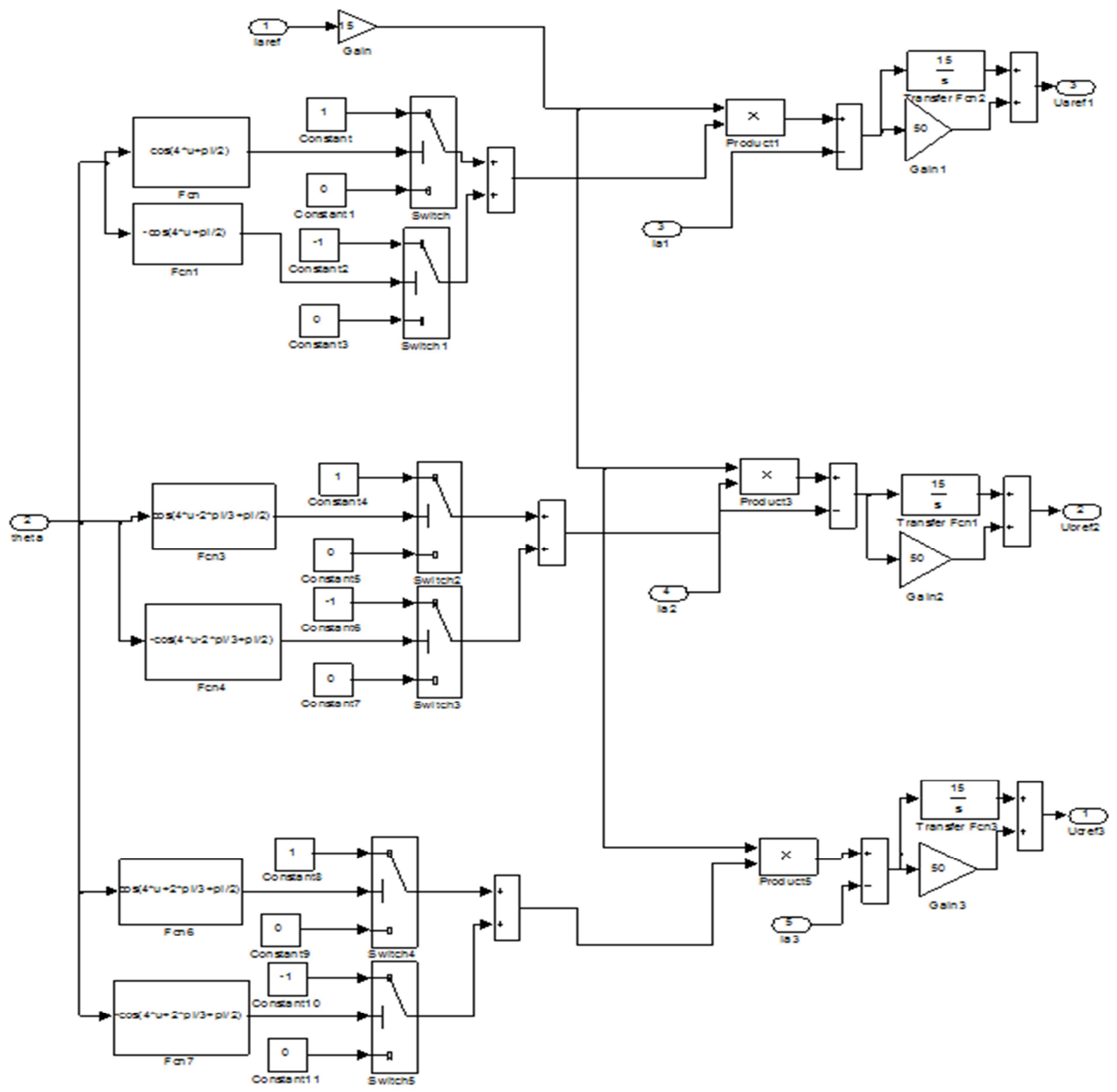

Figure 4. Simulink model of currents regulators. 


\section{Current Regulators}

The reference current generator allows to generating three currents with trapezoidal shapes and phase shifted relative to each other by an angle equal to $120^{\circ}$ electrical. This three phase currents are out in phase with back electromotive forces to minimize consumption and its amplitudes are controlled by the speed controller. Three control loops are used to convert currents to the three reference voltages of the motor.The model of the reference current generator is implanted under the Matlab / Simulink environment as shown in figure 4 [3].

\section{Model of the Back Electromotive Forces}

Thethreebackelectromotiveforcesareestimatedfromthefollo wingthreeequations:

$$
\begin{aligned}
& a=\cos \left(p \times \Omega \times t+\frac{\pi}{2}\right) \\
& b=\cos \left(p \times \Omega \times t-\frac{2 \times \pi}{3}+\frac{\pi}{2}\right) \\
& c=\cos \left(p \times \Omega \times t-\frac{4 \times \pi}{3}+\frac{\pi}{2}\right)
\end{aligned}
$$

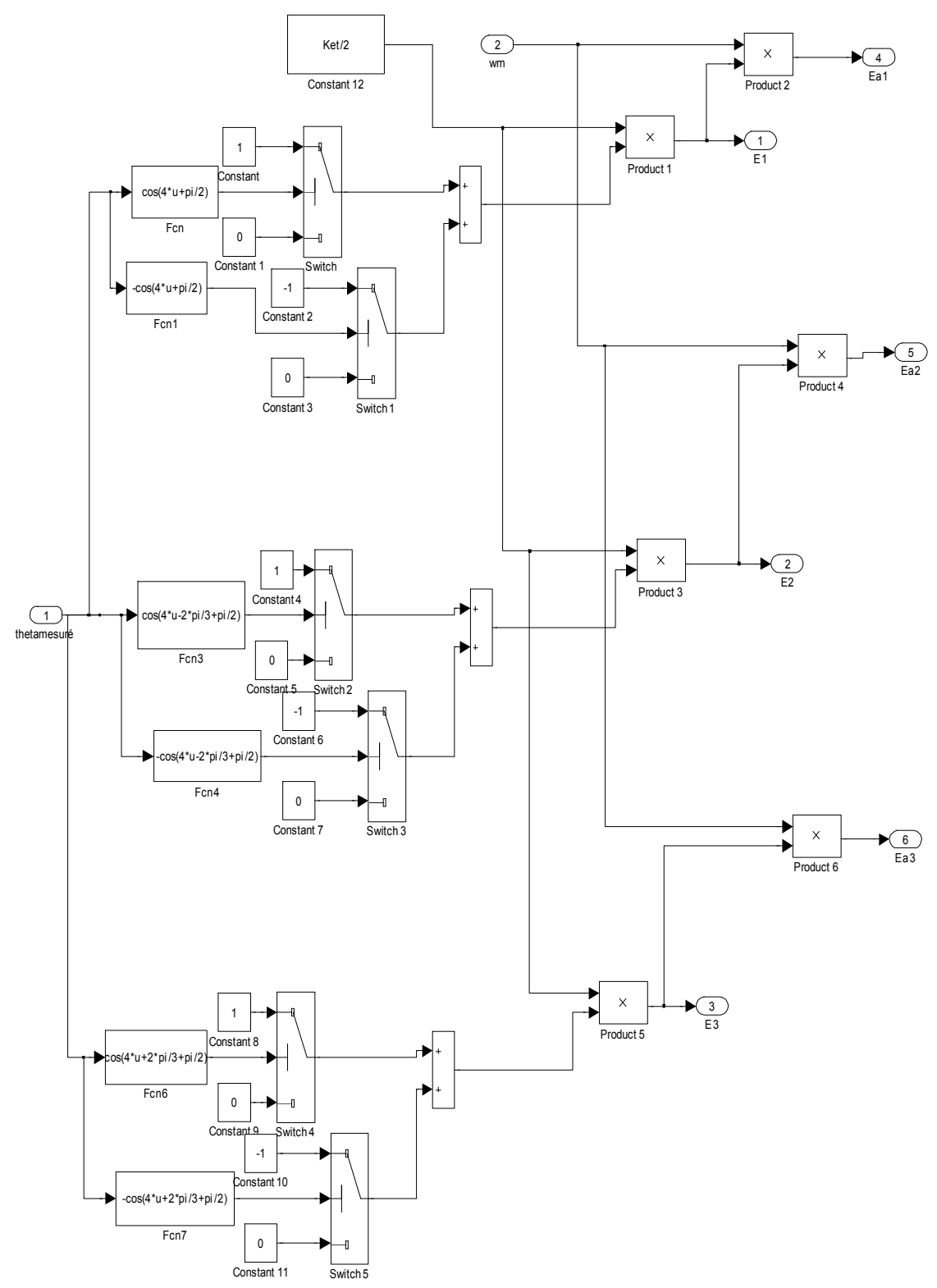

Figure 5. Simulinkmodelofthebackelectromotiveforces. 
The models of the back electromotive forces $\left(\mathrm{e}_{1}, \mathrm{e}_{2}, \mathrm{e}_{3}\right)$ are estimated from the following algorithm [3]:

\{Begin

if

a $>1 / 2$;

$\mathrm{a} 1=1 / 2 \cdot \mathrm{K}_{\mathrm{e}} \cdot \Omega$ :

else

a1 $=0$;

if

$\mathrm{a}<-1 / 2$;

a2 $=-1 / 2 \cdot K_{e} . \Omega$;

else

a2 $=0$;

$\mathrm{e} 1=\mathrm{a} 1+\mathrm{a} 2$;

if

b $>1 / 2$;

b1 $=1 / 2 . \mathrm{K}_{\mathrm{e}} \Omega$ :

else

b1 $=0$;

if

b $<-1 / 2$; b2=-1/2 $\mathrm{K}_{\mathrm{e}} . \Omega$;

else

b2 $=0$;

$\mathrm{e}_{2}=\mathrm{b} 1+\mathrm{b} 2$;

if

c $>1 / 2$;

$\mathrm{cl}=1 / 2 . \mathrm{K}_{\mathrm{e}} \Omega$ :

else

$\mathrm{c} 1=0$;

if

c $<-1 / 2$;

c2 $=-1 / 2 . K_{e} . \Omega$;

else

c2 $=0$;

$\mathrm{e}_{3}=\mathrm{c} 1+\mathrm{c} 2$;

end .

With $\mathrm{K}_{\mathrm{e}}$ is the back electromotive constant and $\Omega$ is the motor angular speed.

The Simulink model of the back electromotive forces is illustrated by the figure 5 .

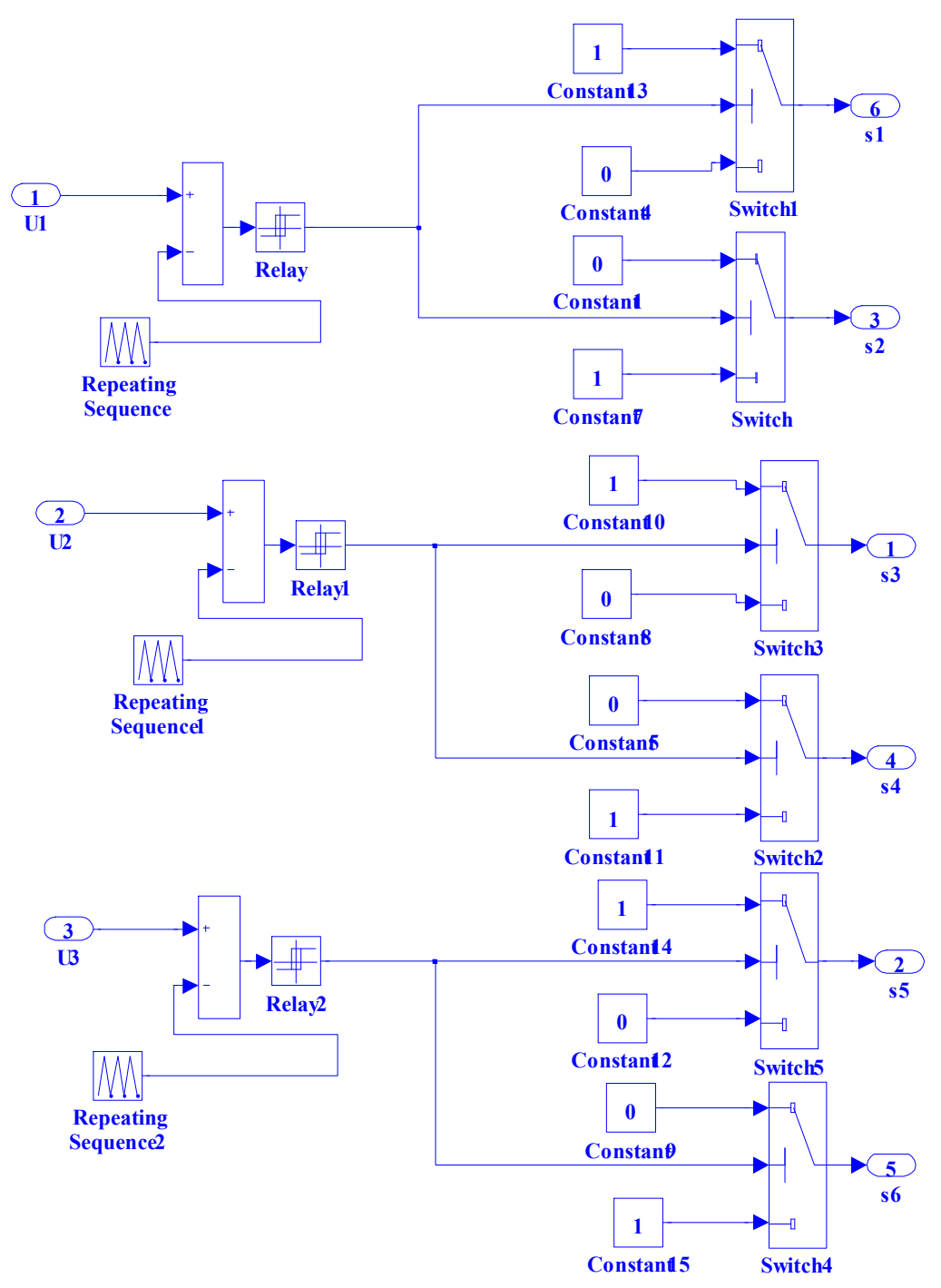

Figure 6. Simulinkmodelofcontrolsignalsgenerator. 


\section{Generator of the Control Signals}

The control signal generator compares the three reference voltages to a triangular signal with frequency significantly higher than the frequency of the voltages provided by the currents regulators. The output of each comparator attacks an hysteresis variant between 0 and 1 for outputting the signals for controlling the IGBTs S1, S3 and S5. The speed controller and current controller adjusts the pulse width of the control signals so as to impose currents in phase with the back electromotive forces and minimize the error between the reference speed and the speed of response. Signals for controlling the IGBTs S2, S4 and S6 are respectively complementary to the signals S1, S3 and S5. To prevent short circuits, control pulses S2, S4 and S6 are shortened to avoid duplication between two signals control arm. The Simulink model of the generator control signals is shown in figure 6 .

\section{Global Model of the Power Chain}

The coupling of different models of the power train of the electric car leads to the overall model implanted under the Matlab / Simulink environment according to the figure 7.

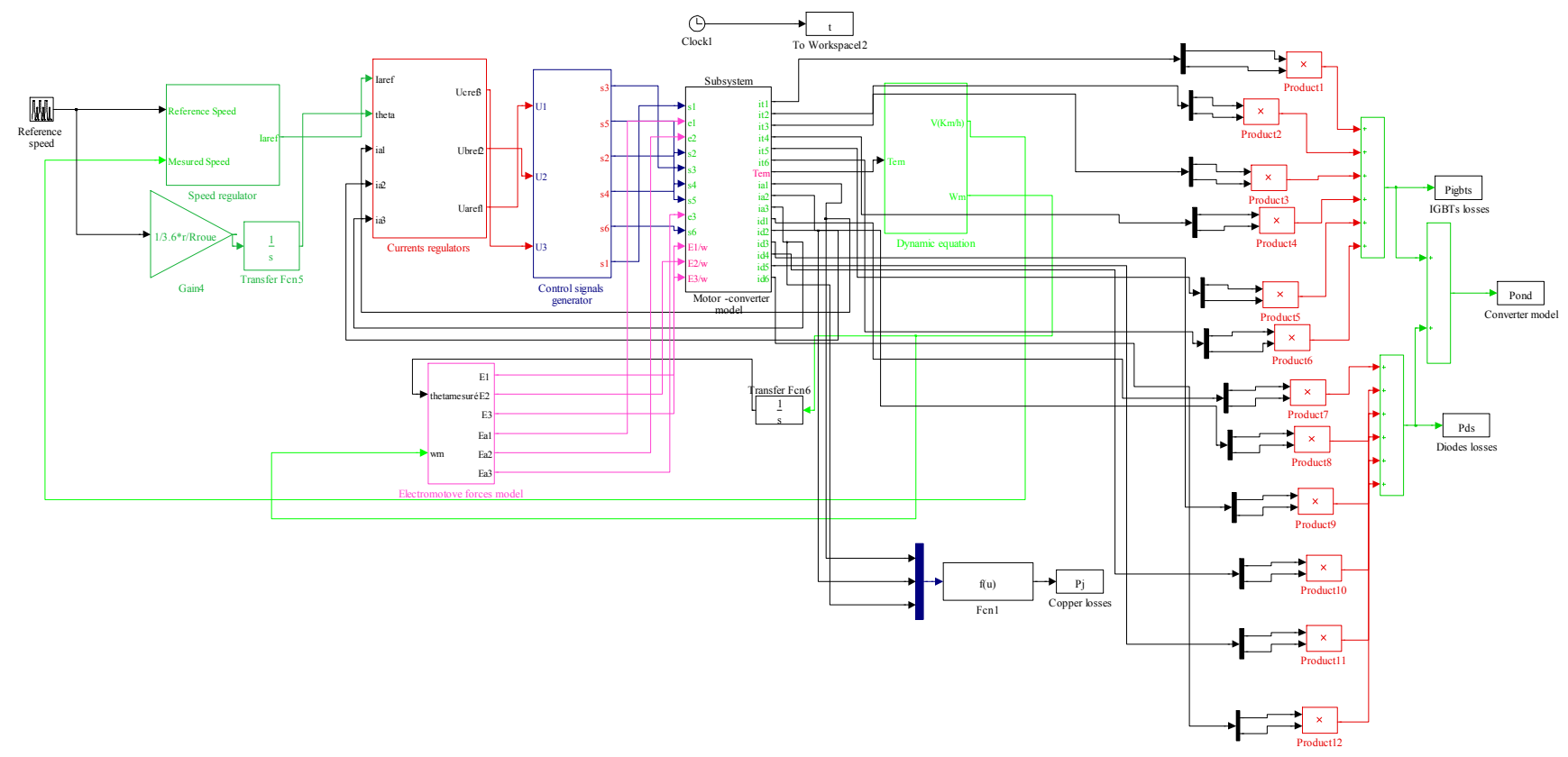

Figure 7. Global model of the power chain.

\section{Simulation Results}

The speed of response for a given travels is illustrated by the figure 8 :

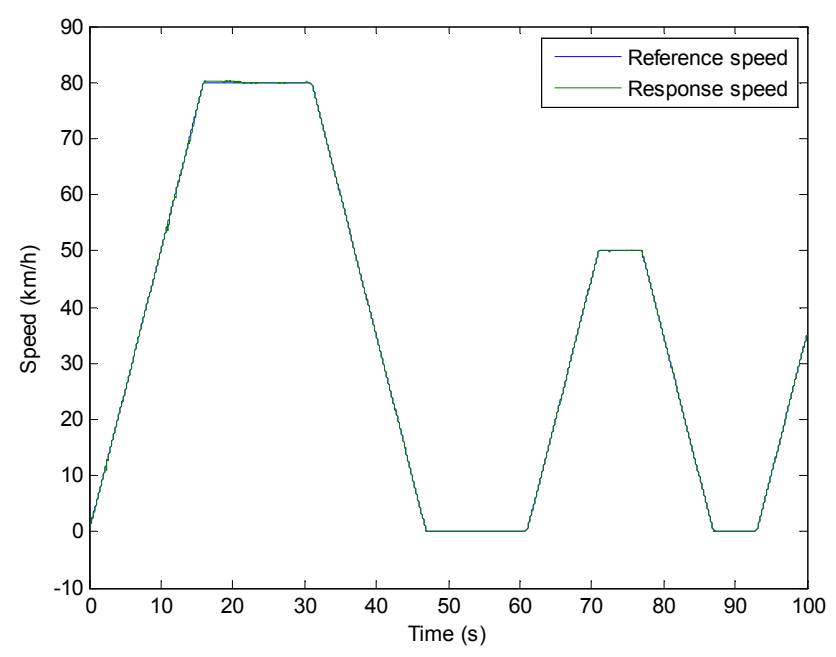

Figure 8. Responsespeed.
Figure 8 shows that the response speed follows with great accuracy the reference speed, which shows the effectiveness of the chosen control technology.

Figure 9 shows the evolution of the motor phase current.

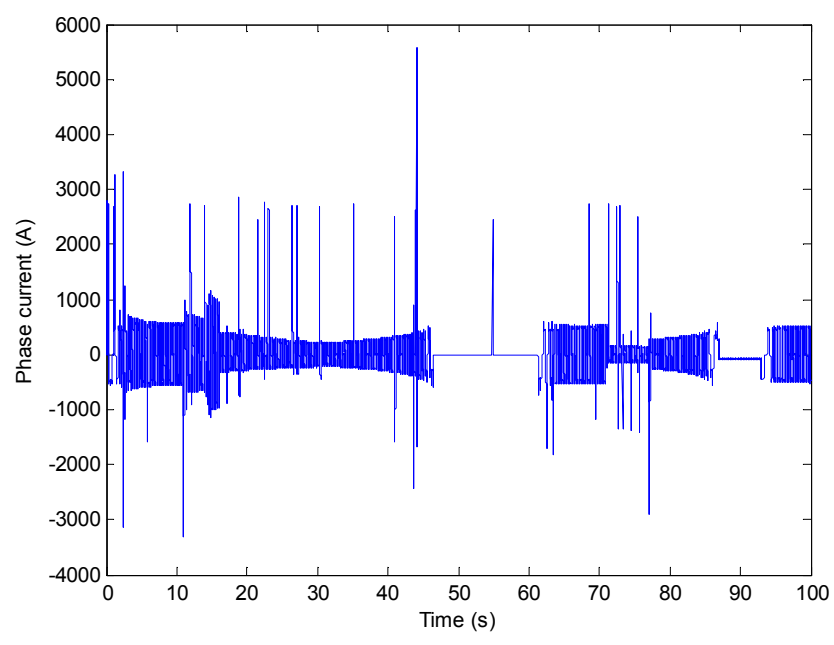

Figure 9. Phasecurrent. 
Figure 9 shows that the starting current is greatly reduced, leading to reduced energy consumption. This characteristic valid the performance of the selected control technology.

Figure 10 shows the evolution of the electromagnetic torque of the engine:

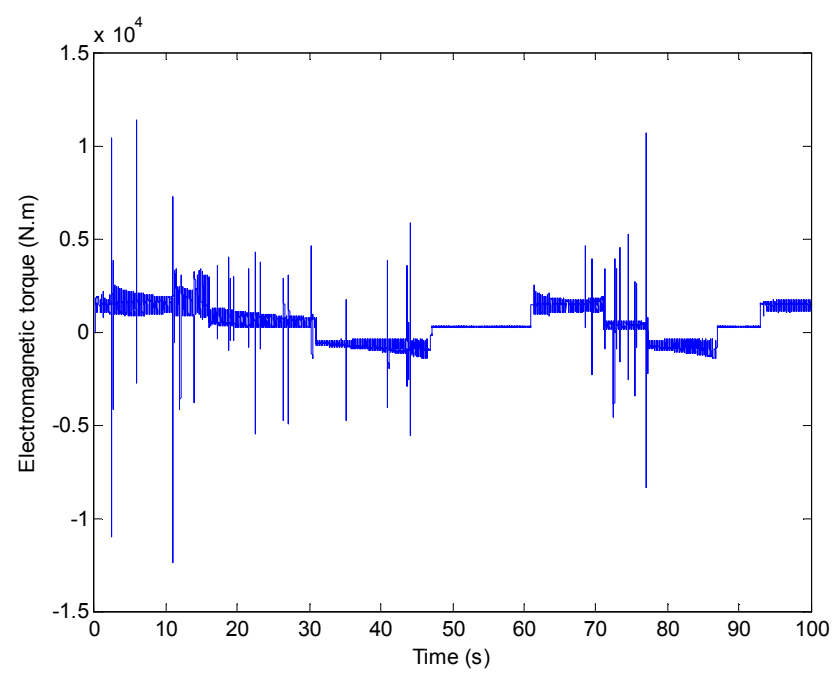

Figure 10. Electromagnetictorque.

The electromagnetic torque (Figure 10) has negative values since during generator operation phases, the engine torque is reversed.

Figure 11 shows the curves of the phase voltage and phase current.

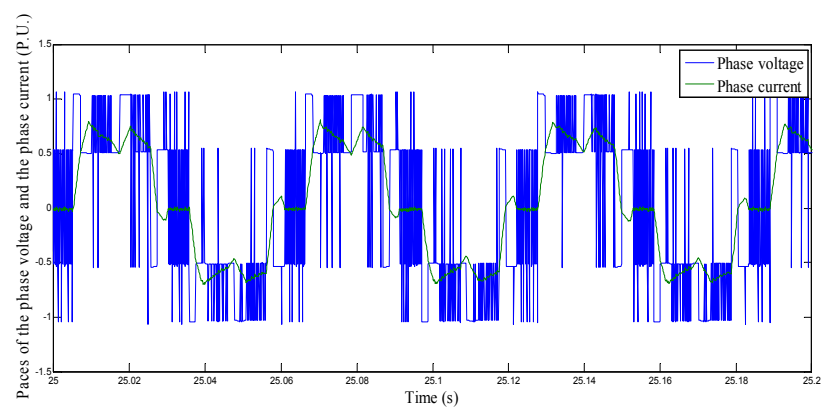

Figure 11. Paces of the phase voltage and phase current.

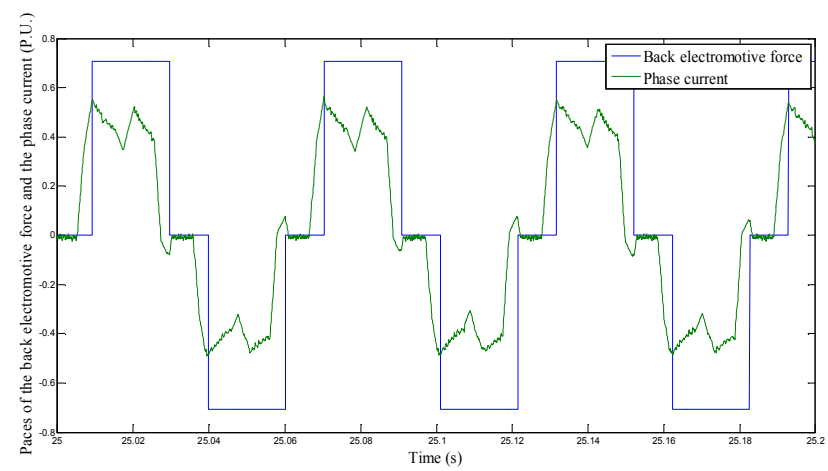

Figure 12. Paces of the back electromotive force and the phase current.

The shape of the phase current is close to a trapezoidal shape, which shows the effectiveness of the chosen control technology.

Figure 12 illustrates the evolution of the back electromotive force and the phase current.

Figure 12 shows that there is a slight phase, reflecting the importance of the electric constant of the motor and low switching frequency.

Figure 13 illustrates the evolution of copper losses [12].

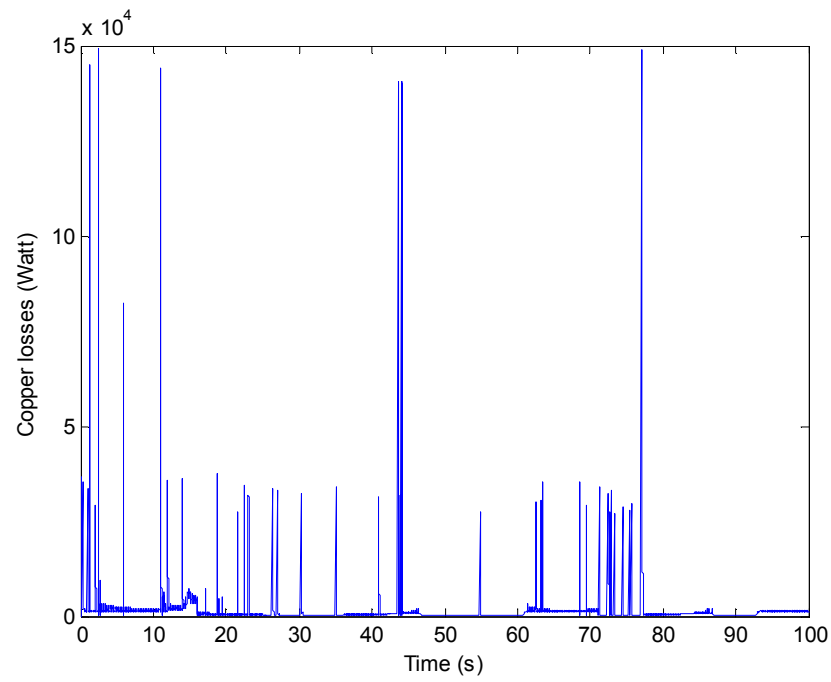

Figure 13. Copper Losses.

The copper losses show peaks during heavy acceleration phases related to high stator currents. The average value of the copper losses is small view that the control technology imposes currents in phases with the back electromotive forces leading to a reduction current for a fixed power need.

Figure 14 illustrates the evolution of the losses in the inverter [12].

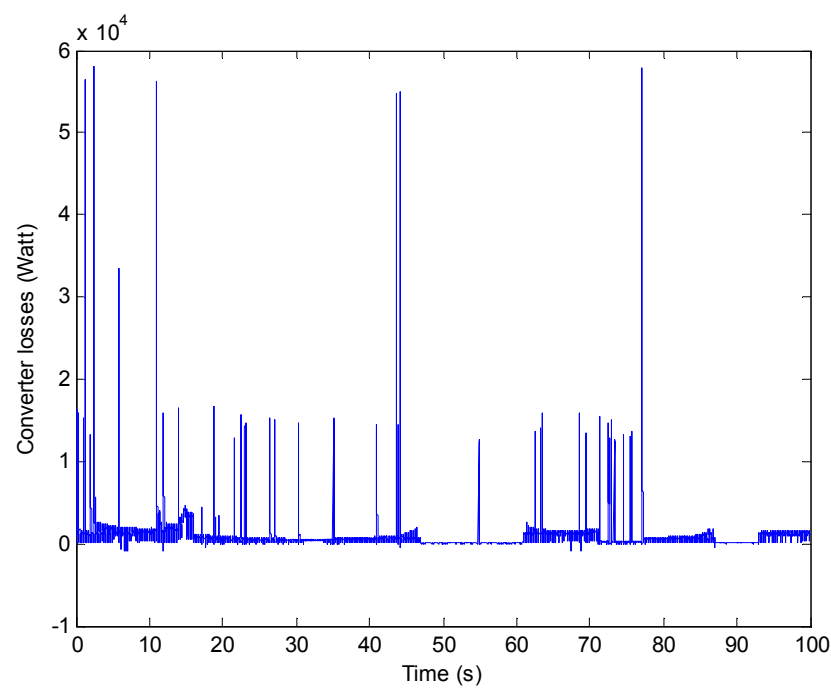

Figure 14. Inverter losses.

The losses in the inverter show peaks during heavy acceleration phases related to high stator currents. The average value of losses in the inverter is small view that the control technology imposes currents in phases with the back electromotive forces leading to a reduction of the phase 
current for a fixed power need.

Figure 15 shows the evolution of the iron losses dissipated in the motor [12]:

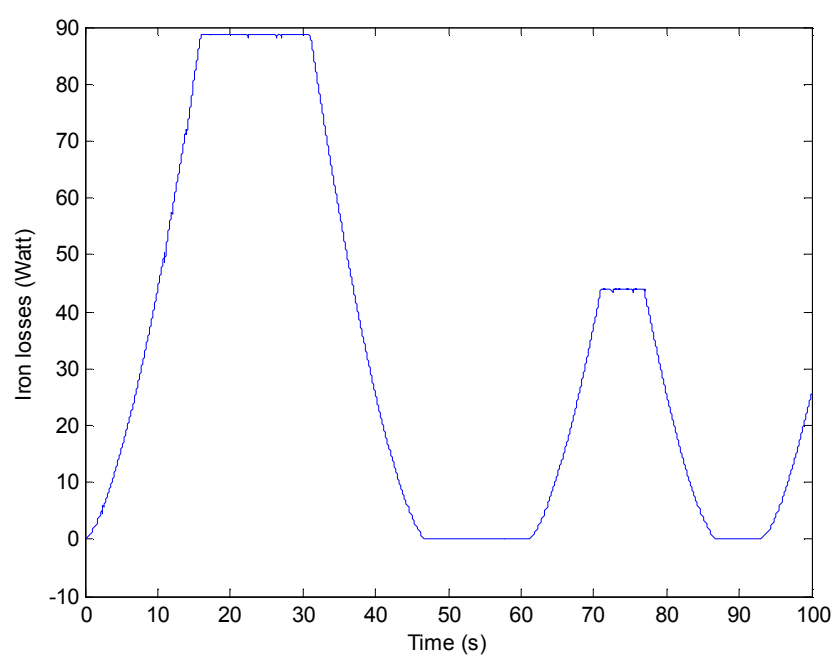

Figure 15. Iron losses.

Figure 15 shows that the pace of the iron losses follows the curve of the speed since the iron losses are proportional to the frequency. These losses are small since the speed of the drive shaft is low (addition of a gear speed amplifier to reach the maximum speed).

Figure 16 Illustrates the evolution of mechanical losses in the engine [12].

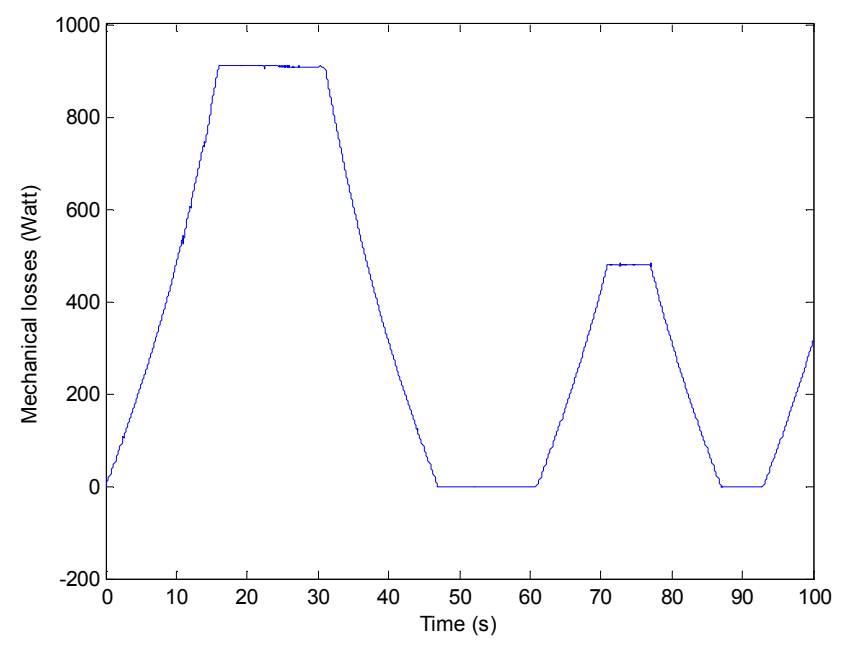

Figure 16. Mechanical losses.

The mechanical losses in the motor evolve in a shape close to the shape of the car's speed cycle since they are proportional to the speed.

\section{Conclusion}

A power chain modeling approach was presented based on the trapezoidal control, including the losses of the power train of an electric car. This modeling approach is parameterized, leading to a problem of optimization of the parameters influencing the losses which leads to an improvement in the autonomy. This model approach is implanted under the simulation environment Matlab-Simulink. Simulation results are encouraging and open track search for work optimization and experimental validation of the developed model.

\section{References}

[1] Aicha Khlissa, Houcine Marouani, Souhir Tounsi, Systemic Design and Modelling of a Coiled Rotor Synchronous Motor Dedicated to Electric Traction, American Journal of Electrical Power and Energy Systems. Special Issue: Design, Optimization and Control of Electric Vehicles: (DOCEV). Vol 4 No. 2-1, 2015, pp. 1-7. doi: 10.11648/j.epes.s.2015040201.11.

[2] Souhir Tounsi, Methodology for Electrothermal Characterization of Permanent Magnet Motor and Its Equivalent to Coiled Rotor, American Journal of Electrical Power and Energy Systems. Special Issue:Design, Optimization and Control of Electric Vehicles: (DOCEV). Vol 4, No. 2-1, 2015, pp. 8-16. doi: 10.11648/j.epes.s.2015040201.12.

[3] Aicha Khlissa, Houcine Marouani, Souhir Tounsi, Trapezoidal Control of a Coiled Synchronous Motor Optimizing Electric Vehicle Consumption, American Journal of Electrical Power and Energy Systems. Special Issue: Design, Optimization and Control of Electric Vehicles: (DOCEV). Vol. 4, No. 2-1, 2015, pp. 17-25. doi: 10.11648/j.epes.s.2015040201.13.

[4] Moez Hadj Kacem, Souhir Tounsi, Rafik Neji, Determination of the Parameters of the Synchronous Motor with Dual Excitation, American Journal of Electrical Power and Energy Systems. Special Issue: Design, Optimization and Control of Electric Vehicles: (DOCEV). Vol. 4, No. 2-1, 2015, pp. 26-32. doi: $10.11648 /$ j.epes.s.2015040201.14.

[5] SouhirTounsi, Modelling and Control of Electric Vehicle Power Train, American Journal of Electrical Power and Energy Systems. Special Issue:Design, Optimization and Control of Electric Vehicles: (DOCEV). Vol. 4, No. 2-1, 2015, pp. 33-41. doi: 10.11648/j.epes.s.2015040201.15.

[6] Mariem Ben Amor, Souhir Tounsi, Mohamed Salim Bouhlel, Design and Optimization of Axial Flux Brushless DC Motor Dedicated to Electric Traction, American Journal of Electrical Power and Energy Systems. Special Issue: Design, Optimization and Control of Electric Vehicles: (DOCEV). Vol 4, No. 2-1, 2015, pp. 42-48. doi: 10.11648/j.epes.s.2015040201.16.

[7] Souhir Tounsi, Design and Optimization of Axial Flux Brushless DC Generator Dedicated to Generation of Renewable Energy, American Journal of Electrical Power and Energy Systems. Special Issue: Design and Monitoring of Renewable Energy Systems (DMRES). Vol. 4, No. 3-1, 2015, pp. 1-5. doi: 10.11648/j.epes.s.2015040301.11.

[8] Wiem Nhidi, Souhir Tounsi, Mohamed Salim Bouhlel, Design and Modeling of a Synchronous Renewable Energy Generation System, American Journal of Electrical Power and Energy Systems. Special Issue: Design and Monitoring of Renewable Energy Systems (DMRES). Vol. 4, No. 3-1, 2015, pp. 6-11. doi: 10.11648/j.epes.s.2015040301.12. 
[9] Houcine MAROUANI and Souhir TOUNSI: Design of a Coiled Rotor Synchronous Motor Dedicated to Electric Traction. Journal of Electrical Systems (JES), Volume 10, Issue 3, (September 2014).

[10] Souhir TOUNSI, Ibrahim BEN SALAH and Mohamed Salim BOUHLEL :Design and control of axial flux Brushless DC motor dedicated to Electric traction. Journal of Automation \& Systems Engineering (JASE), Volume 8, Issue 2, (June 2014).
[11] Ajmia BELGACEM and Souhir TOUNSI: Optimal Control of Electric Vehicle Power Chain. Journal of Automation \& Systems Engineering (JASE), Volume 8, Issue 4, (December 2014).

[12] S. TOUNSI « Losses modelling of the electromagnetic and IGBTs converters », International Int. J. Electric and Hybrid Vehicles (IJEHV), Vol. 5, No. 1, 2013, pp: 54-68. 